\title{
A qualidade dos espaços públicos de lazer na urbanização contemporânea: o caso das periferias do município de Campinas
}

\author{
The quality of leisure spaces in contemporary \\ urbanisation: the case of the suburs of Campinas, Brazil
}

\section{Sidney Piochi Bernardini Carolina Guida Cardoso do Carmo}

\section{Resumo

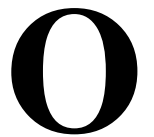

rápido e desigual processo de urbanização no Brasil nos últimos 50 anos tem trazido desafios para a implantação e gestão das áreas de lazer nas periferias das grandes cidades. Este artigo analisa e discute como os espaços livres de uso público previstos nos projetos de loteamento em regiões periféricas do município de Campinas, no estado de São Paulo, foram tratados pela municipalidade entre 1970 e 2010. No caso daqueles convertidos em áreas de lazer, a pesquisa procurou verificar se alguns atributos referenciados pela literatura foram considerados, tomando como recorte territorial de análise duas regiões opostas do ponto de vista da configuração socioeconômica de sua população para posterior comparação entre elas. Os resultados demonstraram que a larga maioria desses espaços livres de uso público não teve intervenções para torná-los áreas de lazer. Além disso, diferença em termos de tratamento naqueles que tiveram intervenções foi constatada entre as duas regiões analisadas. Enquanto na região nordeste, predominantemente ocupada por população de maior poder aquisitivo, as áreas de lazer possuem menos acessibilidade social e melhor qualidade paisagística, na região sudeste, ocupada predominantemente por população de baixa renda, as áreas de lazer são mais acessíveis e mais coesas, mas menos equipadas e com menor qualidade paisagística.

Palavras-chave: Áreas de lazer. Espaços livres de uso público. Praças. Urbanização contemporânea.

\begin{abstract}
The fast and unequal process of urbanisation in Brazil in the past fifty years has posed challenges to the implementation and management of leisure areas in low-income suburbs of cities. This paper aims to analyse and discuss how the public open spaces predicted in urban development projects in suburban areas of the municipality of Campinas, in the state of São Paulo, were treated by the municipality between 1970 and 2010. In the case of spaces converted into leisure areas, the study sought to verify whether certain attributes referenced in the literature were considered, analysing two territorial sections from two contrasting regions in terms of the socioeconomic configuration of their populations for subsequent comparison between them. The outcomes show that most of those public open spaces had not had any public interventions to transform them into leisure spaces. Moreover, there was a difference between the two regions in terms of the treatment given to the areas that received interventions. While in the northeastern region, predominantly occupied by a high-income population, the public leisure areas present less social accessibility and better landscape quality, while in the southeast, which is predominantly occupied by a low-income population, the leisure areas are more accessible and more cohesive, but are more ill-equipped and present lower landscaping quality.
\end{abstract}

Keywords: Leisure areas. Public open spaces. Squares. Contemporary urbanisation.

v. 21, n. 2, p. 243-262, abr./jun. 2021.

ISSN 1678-8621 Associação Nacional de Tecnologia do Ambiente Construído.

http: //dx.doi.org/10.1590/s1678-86212021000200524 


\section{Introdução}

A qualidade dos espaços livres de uso público destinados ao lazer é um desafio que permeia as políticas voltadas para as periferias das grandes cidades, considerando não só a quantidade de espaços criados diante do acelerado processo de urbanização que se intensificou nos últimos 50 anos como também as novas demandas da sociedade em sua relação com os espaços públicos. Queiroga (2001) aponta que, em diversos cenários urbanos, de pequenos núcleos a megalópoles, o espaço livre de uso público pode estar condicionado por realidades específicas. Se suas mudanças, em adaptação às necessidades e demandas criadas pela sociedade brasileira, além de seus usos, complexidade e diversidade, são comumente tratadas pelos estudos que se referem ao tema (MACEDO, 1995; SENNETT, 2014; SERPA, 2014), a questão da finalidade para a qual o espaço público é criado muitas vezes não recebe a devida atenção. Suas origens e as bases de sua destinação, via de regra, permanecem inertes diante dos anseios da sociedade.

No conjunto das pesquisas recentes sobre os diversos aspectos presentes nesses tipos de espaços, é possível encontrar abordagens que tratam dos elementos verdes (arborização e superfícies gramadas) como condicionantes de controle de temperatura no território urbano (ANGULURI; NARAYANAN, 2017; BOWLER et al., 2010), do uso desses espaços como promotores de saúde física e mental (SALVO et al., 2017; STEWART et al., 2018; WOOD et al., 2017), e da sua conectividade em contextos mais periféricos, com a malha urbana e com as demandas de seus possíveis usuários (BAHRINI; BELL; MOKHTARZADEH, 2017; FAN et al., 2017; MANTEY, 2017; SCHIPPERIJN et al., 2010). Essa variedade de resultados apresenta uma vasta compreensão sobre a importância dos espaços livres de uso público nas cidades em geral e, mais especificamente, o valor das atividades de lazer que eles podem oferecer para o desenvolvimento humano, em suas diversas dimensões. Se essa parece ser uma questão já bastante investigada e, de certa forma, corroborada pelos resultados apresentados, a prática que se realiza em geral não aponta para a realidade sobre a qual deveriam promover esses benefícios.

No Brasil, a realidade encontrada nas regiões periféricas de nossas cidades parece refletir o contrário do que o campo científico recomenda para a constituição das áreas livres e de lazer. É possível entender a expansão periférica como a resolução de dois objetivos buscados pelas elites há décadas: desadensar o espaço urbano e segregar determinadas classes sociais (VILLAÇA, 2001). Se aqui o processo de globalização enquadra o fenômeno com proporções semelhantes, as especificidades históricas relacionadas à constituição e gestão dos espaços públicos incluem componentes ainda mais complexos. No processo de produção do espaço urbano brasileiro, parte da constituição das áreas públicas destinadas ao lazer se deu a partir da expansão das áreas urbanizadas com a implantação de loteamentos, seguindo ritos legais frágeis. Apenas em 1979, com a promulgação da Lei federal $\mathrm{n}^{\circ} 6.766$, que dispõe sobre parcelamento do solo, esses espaços receberam regras mais adequadas de ordenamento e disciplinamento (BRASIL, 1979), sem que, entretanto, garantissem sua criação, implantação e manutenção (MACEDO, 2010).

O objetivo deste artigo é apresentar a atual condição dos espaços livres de uso público destinados ao lazer nos projetos de loteamento em regiões periféricas do município de Campinas, no estado de São Paulo, juntamente com sua espacialização dentro de seu tecido urbano. Além disso, analisa-se a qualidade das áreas de lazer efetivamente implantadas utilizando-se como referência de análise alguns atributos já consagrados pela literatura, adotando-os como parâmetros para a avaliação da qualidade desses espaços. A pesquisa abarcou os espaços livres de uso público criados entre os anos de 1970 e 2010 em duas regiões específicas do município.

A legislação municipal instituída ${ }^{1}$ no âmbito do recorte temporal determinado para a pesquisa apresentou ao longo desses anos um conjunto variado de definições para esses tipos de áreas, demonstrando a ausência de normalização conceitual. Como consequência dessa variação terminológica, as expressões utilizadas nas plantas dos loteamentos aprovados no período também se modificaram ao longo do tempo ${ }^{2}$. Essa mudança de padrão em relação à nomenclatura disponível na legislação e nas plantas aprovadas dos loteamentos de Campinas, mas também apontada por Lima et al. (1994) como uma problemática massiva nos municípios brasileiros, pode ser parcialmente compreendida pela predisposição da municipalidade em passar a

${ }^{1}$ Tomando o conjunto de normas legais que tratam da questão, foram selecionadas as seguintes leis: Código de Obras Municipal e suas alterações, de 1959, 1992 e 2003, Lei de Uso e Ocupação do Solo, de 1988, os Planos Diretos de 1971, 1991, 1996 e 2006, e Plano Municipal do Verde, de 2016.

${ }^{2}$ Os termos encontrados como denominadores dos espaços livres públicos nas plantas oficiais de aprovação dos empreendimentos estudados foram: i) praça, ii) sistema de lazer, iii) sistema de lazer - praça, iv) sistema de recreio, v) praça - sistema de recreio e vi) áreas verdes - sistema de lazer. 
considerar, no decorrer das décadas, uma sobreposição de funções, passíveis de novas nomenclaturas, conforme apontam Robba e Macedo (2010). Nesse sentido, optou-se por denominar esses espaços destinados nos planos de loteamento como "espaços livres de uso público", em conformidade com a denominação estabelecida pela Lei $n^{\circ}$ 6.766/1979 (BRASIL, 1979), partindo, além disso, de contribuições advindas de pesquisas realizadas nas últimas duas décadas, com destaque para o grupo de pesquisa QuapáSEL, que buscou unificar a conceituação desses espaços de caráter público e livres de edificação em suas diversas possibilidades de uso, como é o caso do lazer/recreação. No caso dos espaços livres de uso público que receberam intervenções do poder público com o objetivo de promover atividades recreacionais, optou-se por adotar, para efeitos da pesquisa, a denominação "áreas de lazer".

A considerar a complexidade do tema e a suposição de que as áreas de lazer nas periferias das grandes cidades não têm sido devidamente qualificadas para permitir sua apropriação pela população moradora, a motivação desta pesquisa baseou-se em duas perguntas principais:

(a) como esses espaços têm sido qualificados do ponto de vista da intervenção paisagística nas periferias das grandes cidades?; $\mathrm{e}$

(b) há diferenças nessa qualificação entre as regiões periféricas contendo perfis populacionais distintos do ponto de vista da renda familiar?

Tomando o caso de Campinas como objeto empírico da pesquisa, busca-se elucidar, em âmbito mais amplo, respostas para a real qualificação e apropriação dos espaços públicos abertos nas periferias urbanas.

\section{Aspectos da segregação socioespacial em campinas}

Além de guardar características que se enquadram bem aos objetivos buscados na pesquisa, Campinas é um município que vem sendo sistematicamente tratado pela literatura nos aspectos relacionados a suas dinâmicas socioeconômicas. Sua urbanização associa-se diretamente ao processo de reestruturação produtiva pela qual passou o Estado de São Paulo, ainda nos anos 1970, e a consequente industrialização tardia que abrigou. $\mathrm{O}$ crescimento urbano que decorreu dessa industrialização tem sido interpretado como um processo de "urbanização dispersa", caracterizado pela presença de tecidos fragmentados formados também por loteamentos fechados e condomínios horizontais (REIS, 2006). Baeninger (1996) afirma que, através da forte propaganda para instalação de indústrias, durante as décadas de 1950 e 1960 foi possível observar um fluxo migratório intenso para a região campineira. A partir desse atrativo de "mão de obra", houve indução no processo de parcelamento do solo, já na década de 1950, concentrado eminentemente na região sudoeste do município, em proximidade às infraestruturas rodoviária e aeroportuária em implantação (BERNARDO, 2002).

A forma de crescimento, vista também nos municípios que futuramente formariam a Região Metropolitana de Campinas, teve como eixo o processo de indução da população de baixa renda para o chamado vetor oeste/sudoeste, com menor valor de solo urbano pari passu a industrialização de grande parte dos municípios da região (BAENINGER, 1996). Abreu (1986) afirma então que esse processo não tem nada de não planejado, uma vez que é reflexo de um fenômeno amplamente estruturado nesses munícipios.

A análise de Cunha e Falcão (2017) possibilitou confirmar a existência de uma segregação socioespacial na RMC a partir da aplicação do índice de Moran ${ }^{3}$, não apenas em grau de separação entre grupos sociais, mas também de agrupamento entre os estratos sociais (relação entre homogeneidade e heterogeneidade). Ao se basear nos dados dos Censos de 2000 e 2010, a pesquisa logrou demonstrar que, nesses dois momentos, os setores classificados como "baixo-baixo" - aqueles em que as famílias em piores condições de renda estavam circundadas por outras em condições muito semelhantes - se concentravam na região sudoeste, sendo possível afirmar que o agrupamento presente nessa região se deu de forma homogênea, contendo grupos sociais de menor poder aquisitivo. Ao mesmo tempo, em oposição, é possível visualizar os padrões alto-alto e baixo-alto nos setores que agregavam famílias de alta renda circundadas por outras de padrão muito semelhante e famílias com más condições sociais circundadas por outras, em condições de melhor localização, respectivamente nas regiões norte e nordeste do município.

${ }^{3} 0$ índice de Moran é um indicador de associação espacial que avalia a existência de conglomerados (clusters) na distribuição espacial de determinada variável, podendo ser calculado de forma localizada (Moran Local) para cada unidade espacial, assim como, a partir destas, obtido como medida geral (Moran Global), estatística que permite estabelecer o grau de aglomeração de unidades semelhantes existente na região analisada. Pelo Moran Local, é possível criar um mapa em que se podem detectar os setores censitários cercados por outros semelhantes ou não. Para mais detalhes, ver Cunha e Jakob (2010) e Cunha e Falcão (2017). 
Ainda de acordo com Cunha e Falcão (2017), a divisão socioespacial na RMC entre áreas "reservadas" para aqueles de maior e menor poder aquisitivo é inequívoca. Corroboram a ideia de similaridade (ou correlação espacial) a partir dos padrões relatados acima, que eles denominam de cordilheiras: a "cordilheira da riqueza", a nordeste, e a "cordilheira da pobreza", a sudoeste, delimitadas pela Rodovia Anhanguera, que secciona toda a RMC na direção sudeste-noroeste. Mudanças nesse padrão, entretanto, vêm ocorrendo desde os anos 1990, na consolidação das características socioeconômicas das duas regiões, mas com uma sensível alteração nos tecidos da região sudoeste, com a presença de núcleos populacionais de maior poder aquisitivo.

Tendo tais dados como principais aportes da presente pesquisa, o recorte geográfico adotou, além dessa variável, as barreiras físicas existentes, definidas por eixos rodoviários, que foram determinantes para a caracterização urbana do município. Tal nitidez em relação às condições socioeconômicas da população que vive em duas regiões periféricas tão diversas tornou oportuna a investigação que se queria realizar, observando-se a constituição das áreas livres de lazer nos processos de urbanização nessas duas realidades. A região sudoeste foi considerada, nesta pesquisa, como a área compreendida entre as rodovias Anhanguera (SP-330), Bandeirantes (SP-348) e Santos Dumont (SP-75), internas ao perímetro urbano, e a região nordeste como a área compreendida entre as Rodovias Dom Pedro I (SP-065) e Adhemar de Barros (SP340), igualmente internas ao perímetro urbano municipal (Figura 1).

Concluída a delimitação geográfica, os próximos passos da pesquisa consistiram em selecionar as áreas de lazer nos loteamentos aí implantados no período delimitado, para sua posterior avaliação e análise.

Figura 1 - Localização das regiões de estudo - sudoeste e nordeste

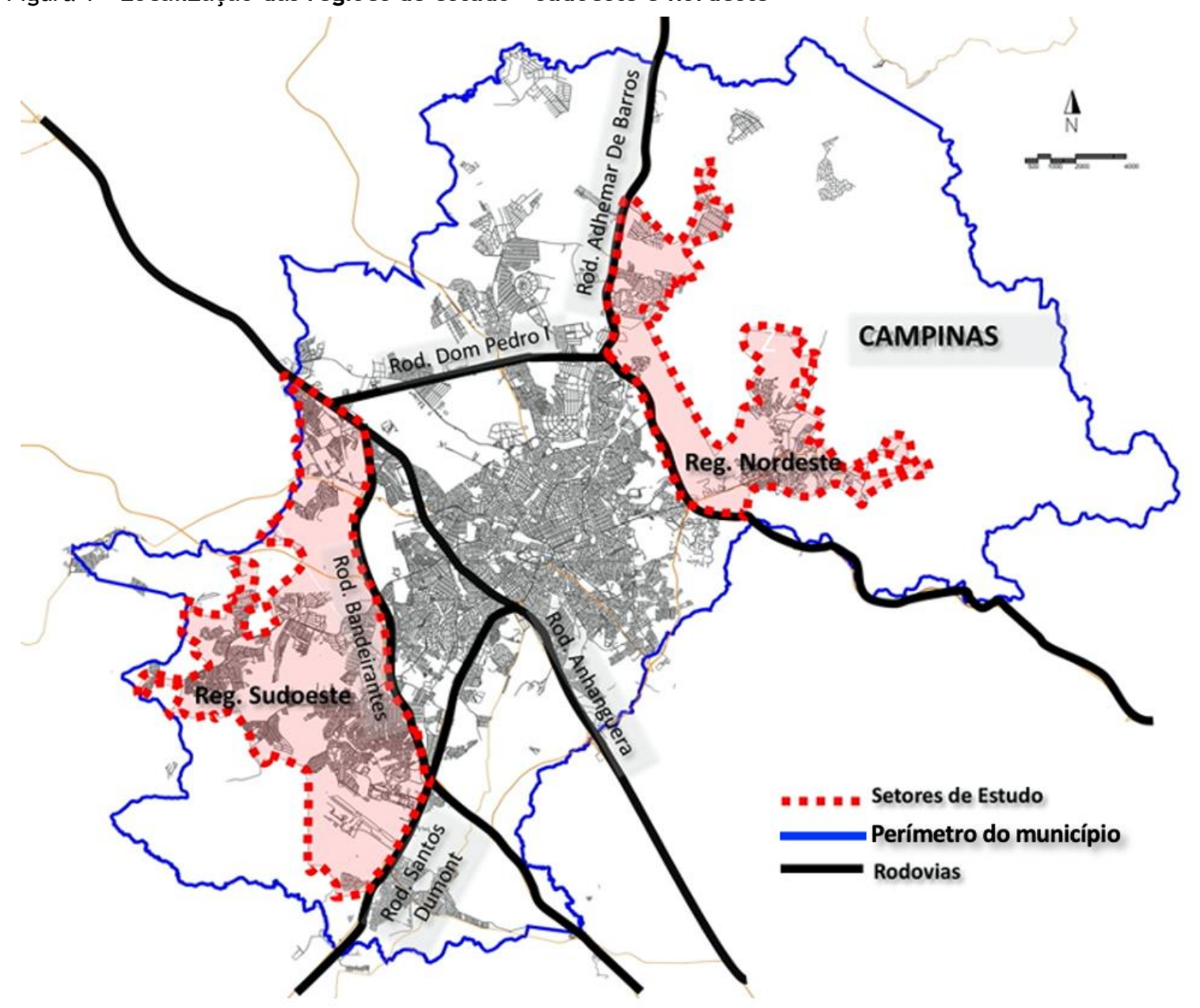




\section{Procedimentos metodológicos}

O percurso metodológico da pesquisa abrangeu os procedimentos a seguir:

(c) cotejamento entre os referenciais teóricos e conceituais relacionados a espaços livres de uso público e de lazer e os conceitos utilizados na legislação municipal, a fim de verificar como a gestão pública compreende essas áreas, buscando relacioná-las com a conceituação e a discussão desenvolvidas no campo acadêmico ${ }^{4}$;

(d) levantamento e análise documental dos principais elementos de pesquisa, incluindo 130 plantas de loteamentos aprovados nas duas regiões selecionadas. Alguns fatores foram sendo considerados para filtrar cada um deles, observando-se o recorte temporal, a efetividade da implantação e, posteriormente, a finalidade da ocupação, quando a apresentavam; e complementaridade a projetos de loteamentos já aprovados (como, por exemplo, loteamentos que consistiam em uma única rua com lotes lindeiros). A pesquisa abrangeu os loteamentos datados entre 1970 e 2010, ano da última planta de loteamento aprovada e cadastrada na prefeitura municipal. A partir da aplicação desses filtros, foram selecionados 40 loteamentos localizados na região sudoeste e 27 na região nordeste, totalizando 67 loteamentos para análise;

(e) classificação dos espaços livres de uso público que foram destinados nos projetos de aprovação em ambos os setores delimitados. Tal classificação partiu de parâmetros definidos na etapa anterior, selecionados através das diversas situações encontradas in loco, servindo como filtros para caracterizar cada uma das áreas. Nessa etapa, esses espaços foram classificados mediante análise de fotointerpretação por imagens de satélite datadas de maio de 2016. Na fotointerpretação, foram comparados os polígonos definidos em projeto com a situação real presente na imagem de satélite, classificando-os em quatro tipos:

- espaços livres de uso público contendo intervenções do poder público, com tratamento paisagístico e/ou implantação de equipamentos de recreação, convertidos, portanto, em áreas de lazer;

- espaços livres de uso público sem nenhum tipo de intervenção do poder público;

- espaços livres de uso público edificados, transformados em equipamentos institucionais público; e

- espaços livres de uso público ocupados para fins de moradia e/ou comércio da população habitante na região. Foram reservados para a análise aqueles classificados como "espaços livres de uso público contendo intervenções do poder público como áreas de lazer";

(f) seleção e estabelecimento dos atributos espaciais já consagrados pela literatura clássica para servir de parâmetros de análise. A definição prévia de tais atributos seguiu algumas indicações, como as de Robba e Macedo (2010), que reforçam as seguintes qualidades espaciais para espaços livres de uso público equipados para o lazer:

- valores ambientais, como ventilação urbana, insolação, ajuda no controle da temperatura;

- valores funcionais, uma vez que, sob esse viés, são importantes espaços para uma opção de lazer urbano; e

- valores estéticos e simbólicos, já que muitas vezes podem se tornar referências na paisagem ou na localização em relação à identidade do bairro ou rua.

Sob tais princípios norteadores, os atributos de análise estabelecidos foram:

- acessibilidade, segundo os conceitos de Carr et al. (1995);

- desenho do espaço, através dos apontamentos de Ashihara (1981);

- coesão, segundo as análises de Sitte (1992);

- localização em relação ao bairro e uso do solo do entorno, a partir das ideias de Jacobs (2000);

- vegetação, baseando-se nos apontamentos de Mascaró e Mascaró (2010); e

- mobiliário urbano e iluminação, a partir das pesquisas apresentadas por Mascaró (2008).

(g) visita de campo nos espaços abertos de lazer selecionados, para a verificação da existência dos atributos ali presentes. As estratégias para a realização das visitas de campo foram diferentes para cada uma das regiões definidas para esta pesquisa, já que quase a totalidade dos loteamentos que contêm os espaços de

${ }^{4}$ Pesquisa bibliográfica elaborada a partir das bases de dados: Scielo, Scopus, WebofScience, Capes Periódicos, Compendex, Biblioteca Digital Brasileira de Teses e Dissertações (BDTD) utilizando os termos chaves "praças", "public squares", "city squares", "espaços públicos", "public spaces", através das combinações de filtros e operadores lógicos booleanos (and, or, not). Também fora feita pesquisa em bases específicas como anais do ENANPUR e Periódico Paisagem e Ambiente, ambas elaboradas entre março e setembro/2016. 
lazer selecionadas na região nordeste é fechada. Se na região sudoeste a visita se estruturou de forma mais previsível, considerando o livre acesso às áreas elencadas, na região nordeste, dependeram da autorização das associações de moradores para a permissão do acesso e o livre desenvolvimento dos trabalhos de observação. Os espaços de lazer visitados nas duas regiões são os presentes nos loteamentos listados no Quadro 1.

É importante destacar que, a partir das premissas conceituais adotadas para a definição e seleção dos atributos, estes foram buscados na literatura clássica e em determinadas obras de referência. Ainda que um conjunto mais amplo da literatura pudesse fornecer critérios mais consagrados historicamente e com embasamento mais filosófico e político por trás de seus entendimentos, do ponto de vista científico, para a avaliação e análise, optou-se por trabalhar com aqueles de acesso mais comum e referenciados no ensino e formação no campo da arquitetura e urbanismo que se refletem nos critérios de projetos paisagísticos elaborados no âmbito do setor público. Além disso, os atributos deveriam ser facilmente observáveis em visita de campo, dado o volume de áreas que deveriam ser visitadas e o tempo estipulado para a pesquisa. Os conteúdos observados em cada um dos atributos são os contidos no Quadro 2.

Tendo esses atributos como filtros de análise aplicados a partir de observação de campo, cada uma das áreas selecionadas foi analisada após sua sistematização em uma matriz de valores, na qual a classificação foi estruturada como:

(a) atende ao atributo, compreendendo as situações em que ele pode ser percebido de forma total e evidente nas áreas analisadas, sem quaisquer tipos de prejuízo;

(b) atende parcialmente ao atributo, compreendendo as situações em que é possível ver a existência de vestígios do atributo analisado, mas cujos benefícios não são totais; e

(c) não atende ao atributo, sendo essas as situações em que não é possível observar nenhum tipo de preocupação ou planejamento da consideração do atributo analisado.

\section{Resultados: dois lados de uma mesma moeda}

$\mathrm{Na}$ região nordeste, caracterizada pela alta concentração de famílias com maior poder aquisitivo, foram encontrados diversos espaços recreacionais equipados nos loteamentos (fechados, em sua maioria), mas que, muitas vezes, se configuravam como lotes privados, e não como áreas públicas, dificultando ainda mais discutir, dentro das permissividades municipais, a compreensão do poder público municipal em relação ao conceito de área de lazer. Essa situação não é igual em todos os loteamentos fechados, mas sua maioria apresenta espaços livres de uso público sem nenhum tipo de equipamento ao lado de lotes condominiais reservados para clubes com a presença de piscinas, quadras poliesportivas e tratamento paisagístico. As áreas de lazer públicas nas regiões mais ricas estão quase ausentes, o que se associa ao modelo de convivência social que toma como premissa a segurança e a privacidade encontradas em locais como shoppings centers e condomínios em geral (QUEIROGA, 2012).

\section{Quadro 1 - Loteamentos com espaços de lazer visitados}

\begin{tabular}{|c|c|}
\hline Região Sudoeste & Região Nordeste \\
\hline Residencial Cosmos, Jardim & $\begin{array}{c}\text { Parque Jatibaia e do Jardim São Francisco, que são os } \\
\text { dois únicos loteamentos abertos selecionados, Ville } \\
\text { Florence, Jardim Novo Maracanã, } \\
\text { Painte Hellene, Arboreto dos Jequitibas, cujos espaços de } \\
\text { lazer existentes estão fora de seus fechamentos, e } \\
\text { Jardim Floresta, DIC, I, DIC II, DIC } \\
\text { VI, Conjunto Habitacional Núcleo } \\
\text { Vida Nova, Jardim Vista Alegre e } \\
\text { Parque Itajaí }\end{array} \begin{array}{c}\text { Botânico, Villa dos Plátanos e Alphaville Dom Pedro, } \\
\text { cujo pedido de solicitação de acesso foi autorizado (os } \\
\text { demais loteamentos fechados existentes nessa região não } \\
\text { foram visitados) }\end{array}$ \\
\hline Total: 17 áreas & Total: 18 áreas \\
\hline
\end{tabular}

248 Bernardini, S. P.; Carmo, C. G. C. do 
Quadro 2 - Síntese dos atributos considerados para análise

\begin{tabular}{|c|c|c|}
\hline Atributo & Autor & Síntese \\
\hline Acessibilidade & $\begin{array}{c}\text { Carr et al. } \\
\text { (1995) }\end{array}$ & $\begin{array}{l}\text { Aspecto primordial para a utilização do espaço. O autor } \\
\text { enfatiza três formas necessárias para promover a } \\
\text { acessibilidade: a física, a visual e a social. Enquanto a } \\
\text { acessibilidade física e visual situa o usuário do ponto de vista } \\
\text { topológico, a acessibilidade social está relacionada com o } \\
\text { controle social e a apropriação dos espaços, viabilizada pela } \\
\text { conexão ao bairro. }\end{array}$ \\
\hline $\begin{array}{c}\text { Desenho do } \\
\text { espaço }\end{array}$ & $\begin{array}{c}\text { Ashihara } \\
\text { (1981) }\end{array}$ & $\begin{array}{l}\text { O solo e as barreiras verticais delimitam o formato do } \\
\text { espaço, permitindo as relações corpóreas e visuais entre os } \\
\text { usuários. A clareza entre os espaços de movimento e de } \\
\text { permanência também devem ser perceptíveis e dependem de } \\
\text { uma setorização. }\end{array}$ \\
\hline Coesão & Sitte (1992) & $\begin{array}{l}\text { Sistema de fechamento da praça pelas edificações } \\
\text { circundantes na busca de um efeito harmônico do conjunto. } \\
\text { A emblemática obra de Camilo Sitte é tomada como } \\
\text { referência para tratar da relação entre as edificações, a área } \\
\text { de lazer e as ruas que as circundam. }\end{array}$ \\
\hline $\begin{array}{l}\text { Localização e } \\
\text { uso do solo do } \\
\text { entorno }\end{array}$ & $\begin{array}{l}\text { Jacobs } \\
(2000)\end{array}$ & $\begin{array}{c}\text { Um dos fatores de maior importância para garantir a } \\
\text { segurança na apropriação dos usuários é a diversidade de } \\
\text { atividades exercidas no interior e no entorno imediato da área } \\
\text { de lazer. A integração de usos do solo diversificados garante } \\
\text { maior atração de públicos diversos, cuja interação pode se } \\
\text { dar no espaço. }\end{array}$ \\
\hline Vegetação & $\begin{array}{l}\text { Mascaró e } \\
\text { Mascaró } \\
(2010)\end{array}$ & $\begin{array}{l}\text { Responsável por fazer a integração entre os elementos } \\
\text { construídos da cidade com o espaço natural e a paisagem. } \\
\text { Várias características e aspectos da vegetação são } \\
\text { importantes para o conforto térmico e acústico dos usuários, } \\
\text { fruição e contemplação paisagística e as condicionantes } \\
\text { ambientais. }\end{array}$ \\
\hline $\begin{array}{l}\text { Mobiliário } \\
\text { urbano }\end{array}$ & & $\begin{array}{l}\text { O mobiliário urbano dá suporte aos vários usos possíveis em } \\
\text { determinada área de lazer, além de contribuir para seu valor } \\
\text { estético. Atende a várias necessidades, tais como descanso, } \\
\text { lazer, esporte, abrigo, limpeza e contemplação. }\end{array}$ \\
\hline Iluminação & $\begin{array}{c}\text { Mascaró } \\
(2008)\end{array}$ & $\begin{array}{c}\text { A iluminação deve ser pensada de acordo com a localização } \\
\text { e necessidade de cada espaço, com os espaços livres } \\
\text { periféricos contextualizados na realidade do bairro, e, assim, } \\
\text { devendo atender às características relacionadas aos usos } \\
\text { realizados (períodos do dia e da noite, concepção } \\
\text { programática, etc.). As iluminações natural e artificial } \\
\text { compõem esse atributo. }\end{array}$ \\
\hline
\end{tabular}

Fonte: adaptado de Carr et al. (1995), Ashihara (1981), Sitte (1992), Jacobs (2000), Mascaró e Mascaró (2010) e Mascaró (2008).

A maioria dos casos nesta região, conforme a Figura 2, foi classificada como espaços livres de uso público sem intervenção do poder público $(91 \%)$ e sem qualquer tipo de equipamento, inclusive de recreação implantado, o que demonstra, de um lado, a omissão da municipalidade quanto às intervenções nessas áreas, tornando-as inaptas para as atividades de lazer e recreação, e, de outro, que elas se tornam ociosas e subutilizadas justamente em regiões onde o preço da terra passa a se valorizar progressivamente com a implantação desses assentamentos, como é perceptível nas Figuras 3 a 6 . Essa análise da região nordeste foi mapeada, como é possível visualizar na Figura 7, demonstrando não haver relação direta entre as áreas de lazer e os principais eixos de acesso dos loteamentos. 
Figura 2 - Análise percentual dos espaços livres de uso público dos loteamentos da região nordeste

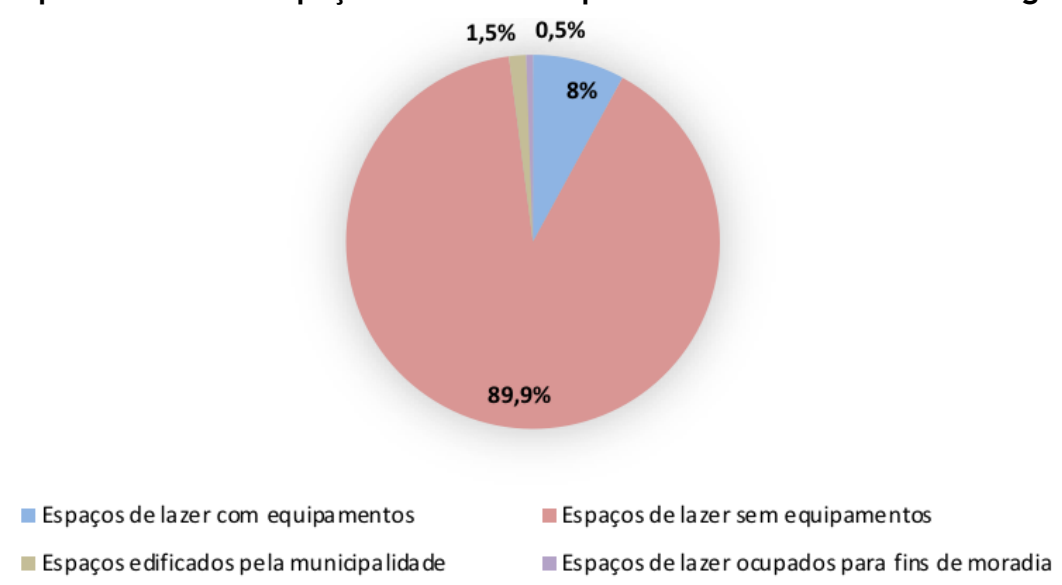

Figura 3 - Áreas de lazer: Arboreto dos Jequitibás

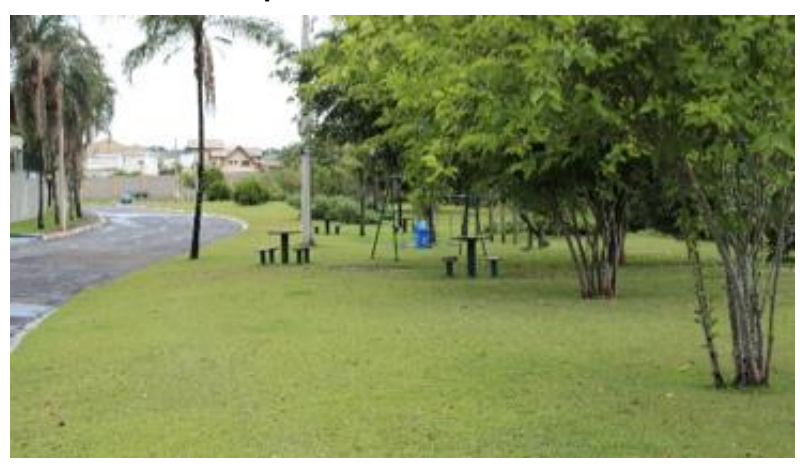

Figura 4 - Áreas de lazer: Alphaville Dom Pedro

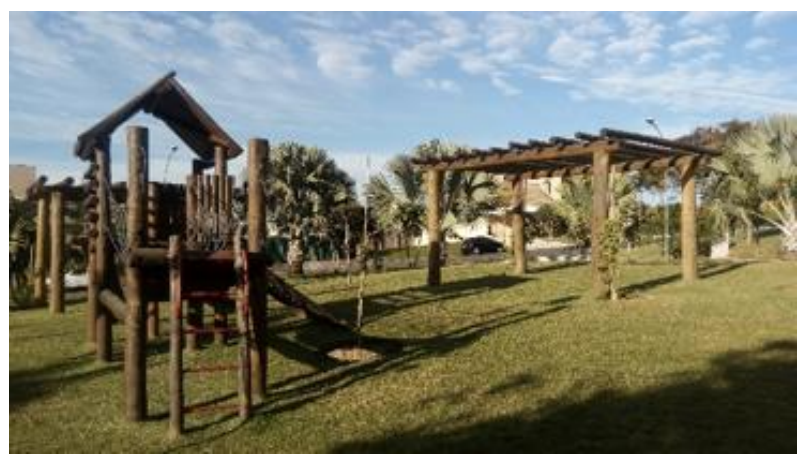

Figura 5 - Áreas de lazer: Caminhos de San Conrado

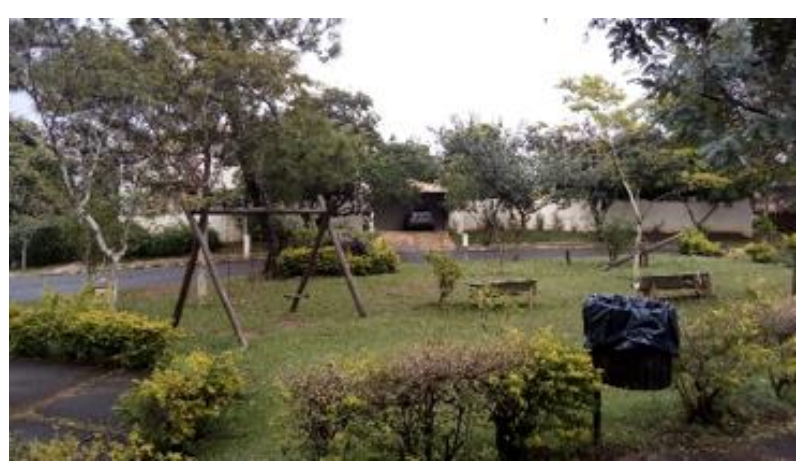


Figura 6 - Áreas de lazer: Vila dos Plátanos

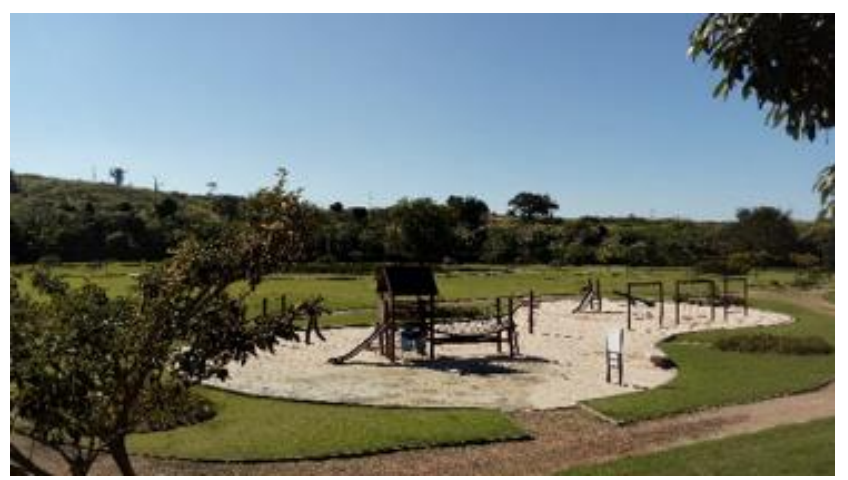

Figura 7 - Situações encontradas nos espaços livres de uso público da região nordeste (classificação in loco)

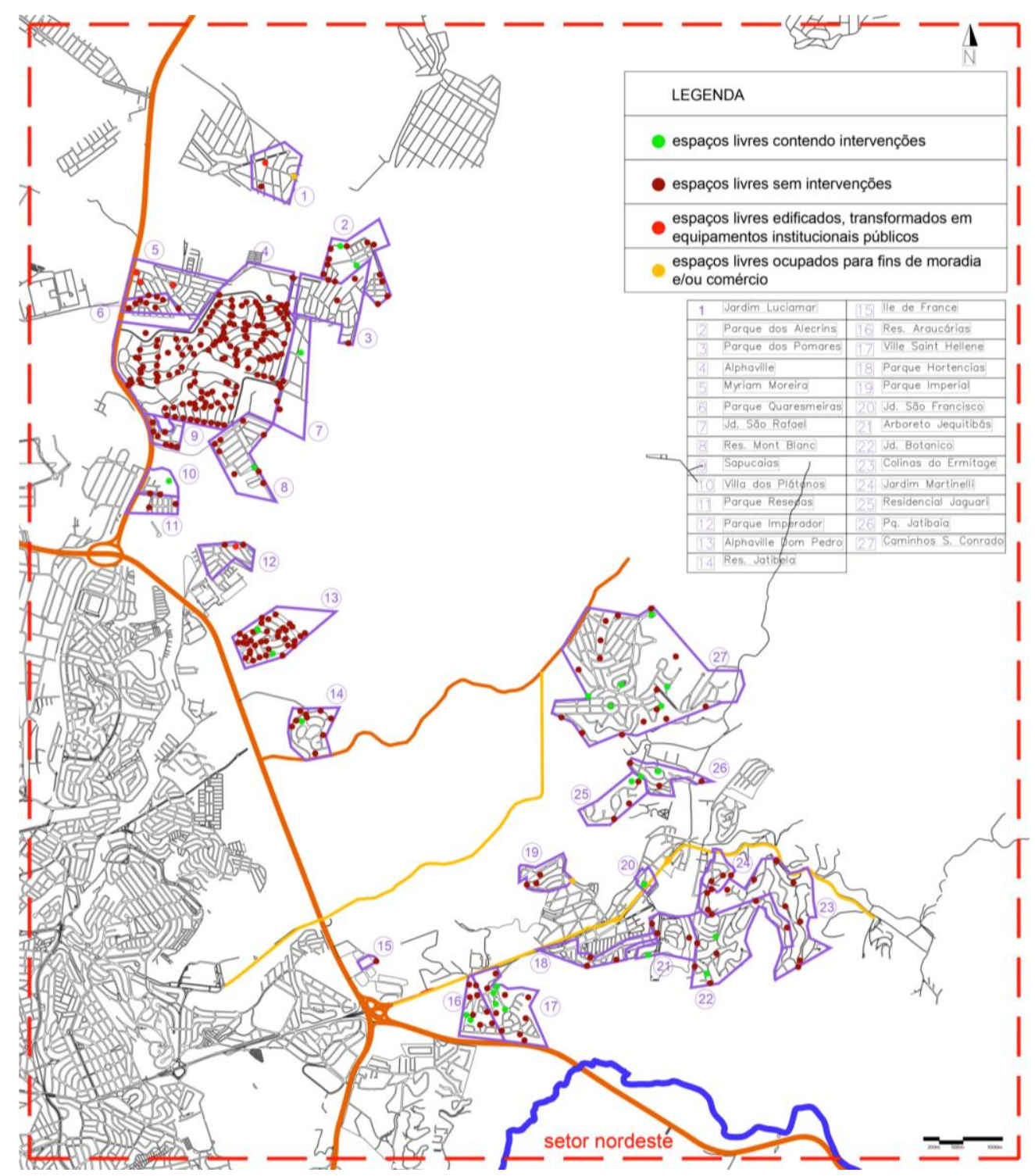


Na região sudoeste, diferentemente da região nordeste, há quase ausência de loteamentos fechados. É possível observar, por outro lado, a forte presença de ocupações para fins habitacionais nos espaços livres de uso público, que estariam destinados ao lazer em sua origem, de acordo com as plantas dos loteamentos. A diversidade de situações encontradas na região sudoeste é mais marcante em comparação àquelas encontradas na outra região. De 168 polígonos de espaços livres de uso público, conforme a Figura 8, 110 $(65 \%)$ estão sem uso ou abandonados, sem nenhuma intervenção do poder público ou qualquer outra utilização por particulares, caracterizados, em sua maioria, por áreas com baixo nível de qualidade espacial, o que já indica, de antemão, a ausência do poder público na gestão dessas áreas, à semelhança da região nordeste. Além disso, a ocupação desses espaços com construções para fins habitacionais e/ou comerciais foi percebida em aproximadamente $17 \%$ deles. Também foi possível observar o percentual de $11 \%$ contendo edificações de uso comunitário construídas pela municipalidade, como escolas e creches. O mapa da Figura 13 também mostra uma configuração diferente da região anterior, já que grande parte das áreas de lazer está mais próxima dos principais eixos de acesso aos loteamentos.

A princípio foram encontradas diversas situações nas quais a atuação da população parece ter sido essencial para a criação e até mesmo manutenção das áreas de lazer, assim como a implantação de alguns equipamentos, ainda que não utilizados por ela, conforme as Figuras 9, 10, 11 e 12. Uma característica recorrente dessa região é a presença de muitos campos de futebol/várzea como equipamento de lazer, ocupando, muitas vezes, a área em sua totalidade. Por sua vez, a característica predominante dos empreendimentos da região nordeste são clubes, como já mencionado, tornando as áreas de lazer inócuas e sem sentido para aquela população, que não tem a intenção de criar fruição pública nas proximidades de seus locais de moradia. Após a aplicação dos atributos presentes na literatura investigada, foi formulada a matriz (Tabelas 1 e 2) que serviu de base para as análises e posterior classificação da qualidade desses espaços.

\section{Figura 8 - Análise percentual dos espaços livres de uso público dos loteamentos da região sudoeste}

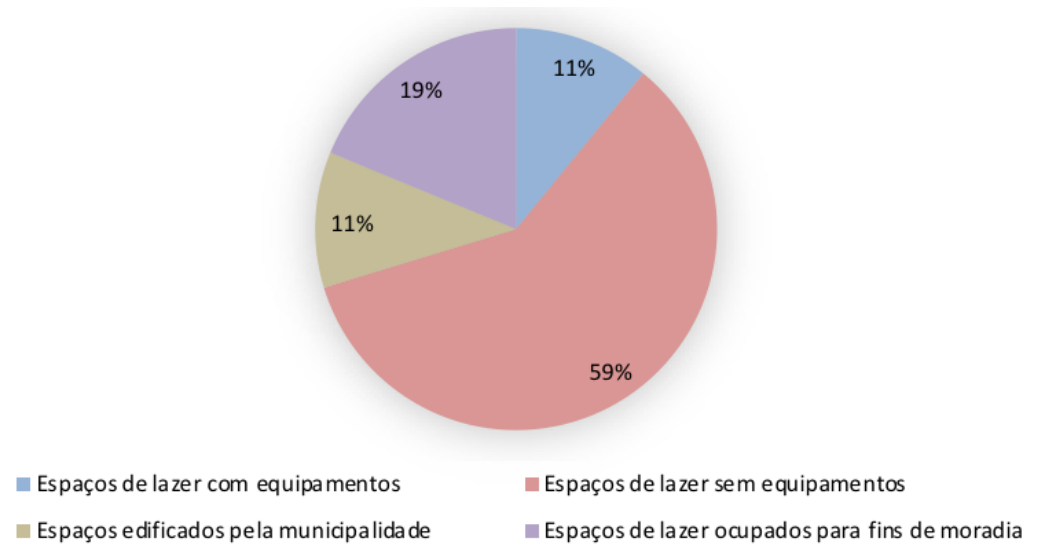

Figura 9 - Áreas de lazer: Jardim Florence

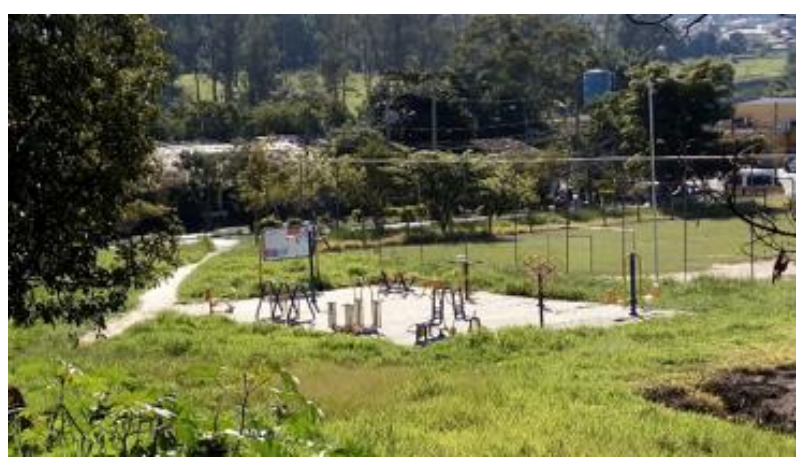

252 Bernardini, S. P.; Carmo, C. G. C. do 
Figura 10 - Áreas de lazer: Parque Valença (Gleba 2)

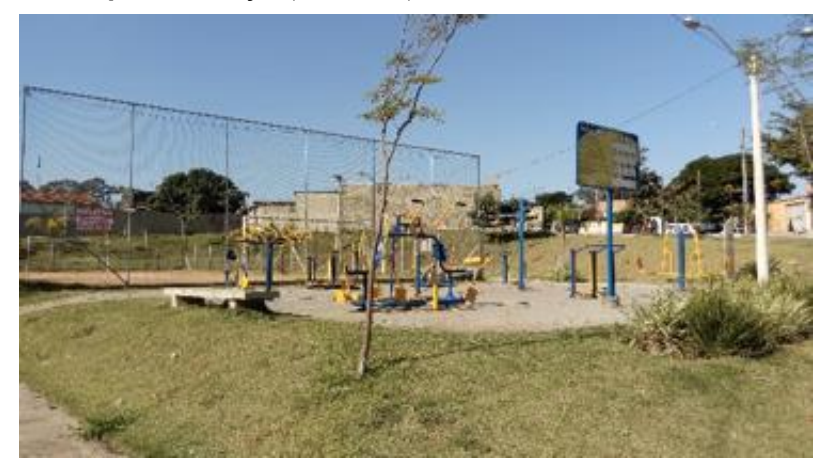

Figura 11 - Áreas de lazer: Bairro DIC II

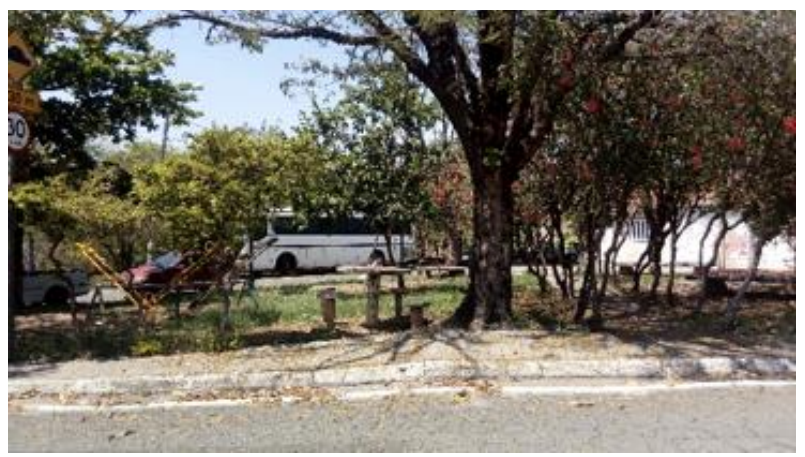

Figura 12 - Áreas de lazer: Bairro DIC VI

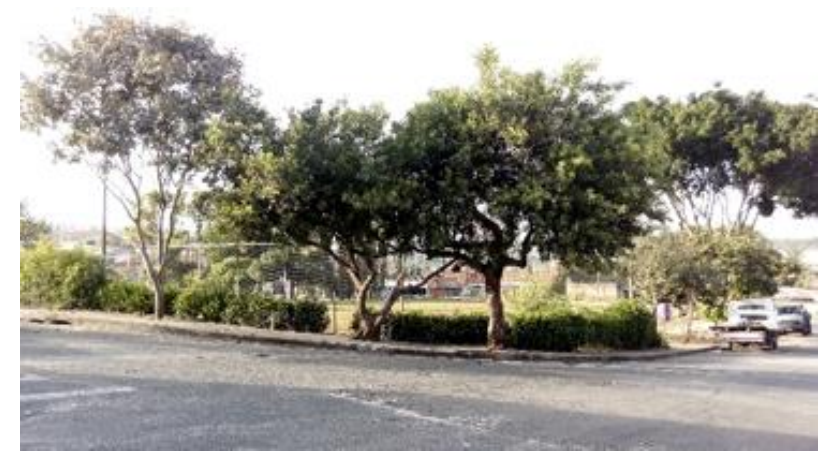


Figura 13 - Situações encontradas nos espaços livres de uso público da região sudoeste (classificação in loco)

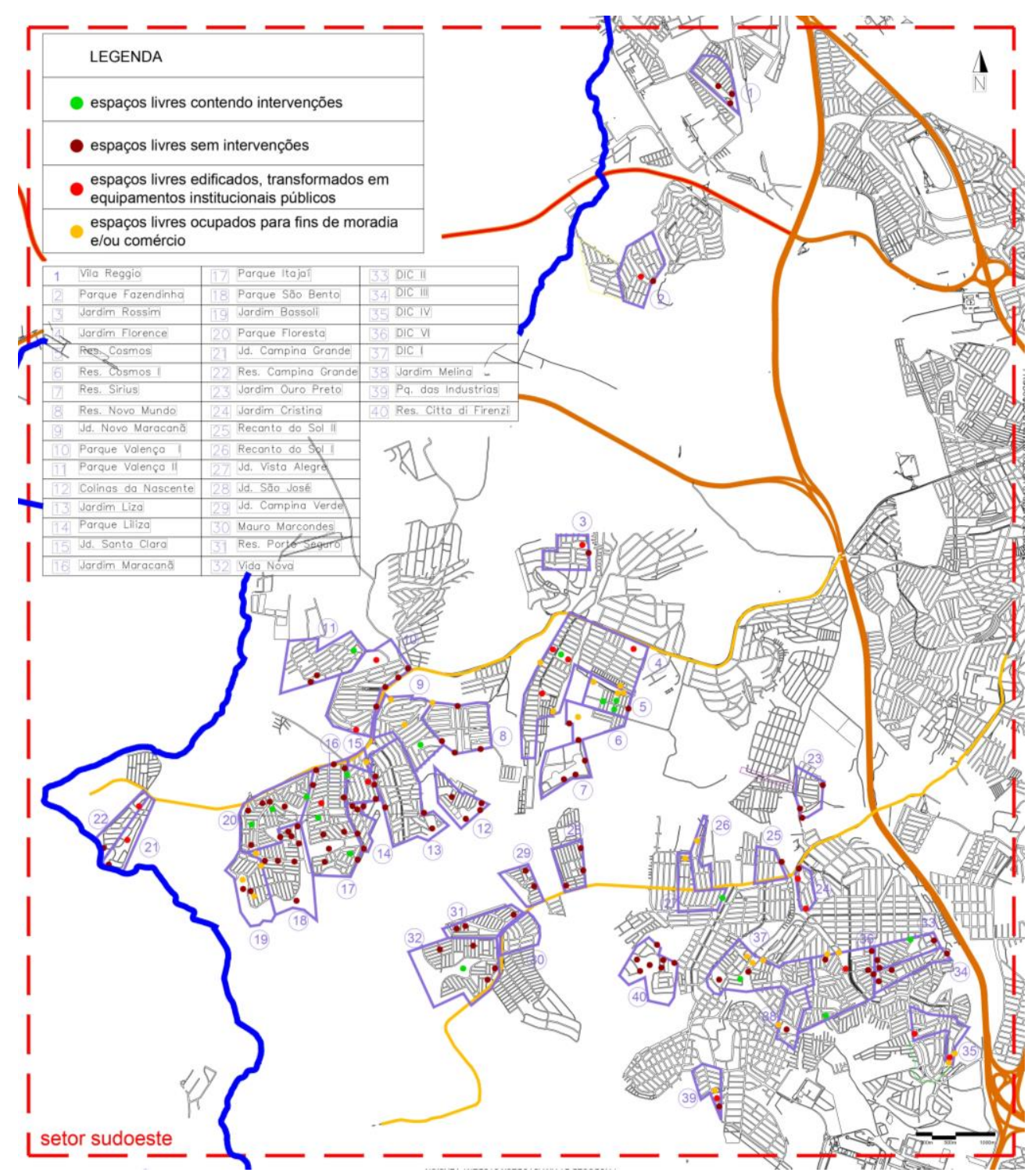




\section{Tabela 1 - Matriz dos atributos - região nordeste}

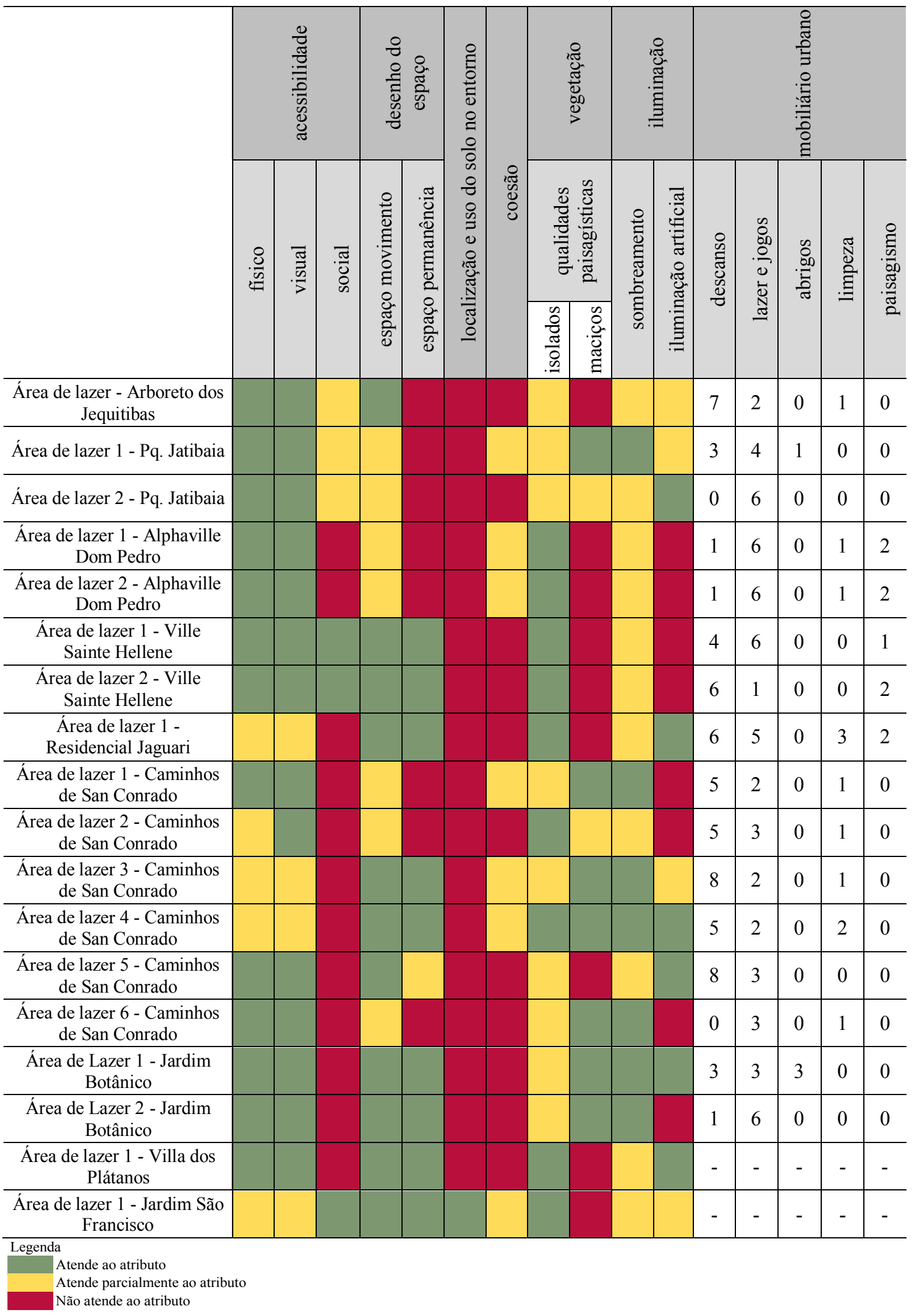


Tabela 2 - Matriz dos atributos - região sudoeste

\begin{tabular}{|c|c|c|c|c|c|c|c|c|c|c|c|c|c|c|c|c|}
\hline & \multicolumn{3}{|c|}{ 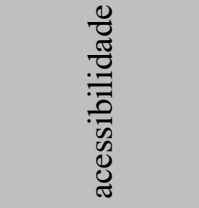 } & \multicolumn{2}{|c|}{ 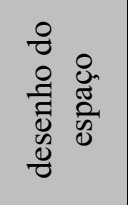 } & \multirow{3}{*}{ 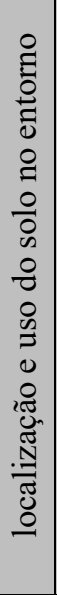 } & \multirow{3}{*}{ 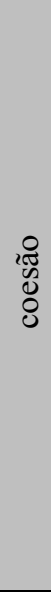 } & \multicolumn{2}{|c|}{ 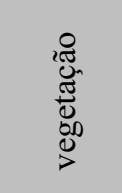 } & \multicolumn{2}{|c|}{ 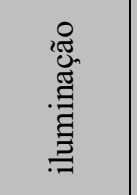 } & \multicolumn{5}{|c|}{ 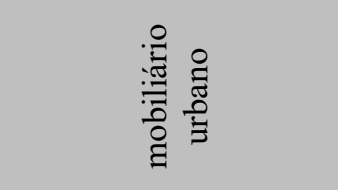 } \\
\hline & \multirow[t]{2}{*}{$\stackrel{\ominus}{\stackrel{\circlearrowright}{\infty}}$} & \multirow[t]{2}{*}{$\begin{array}{l}\bar{\pi} \\
\frac{\pi}{7}\end{array}$} & \multirow[t]{2}{*}{$\begin{array}{l}\bar{\pi} \\
\frac{\pi}{8} \\
0\end{array}$} & \multirow{2}{*}{ 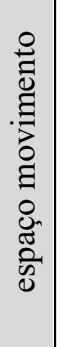 } & \multirow{2}{*}{ 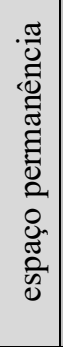 } & & & \multicolumn{2}{|c|}{ 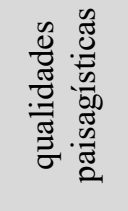 } & \multirow{2}{*}{ 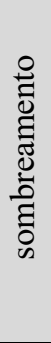 } & \multirow{2}{*}{ 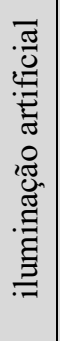 } & \multirow[t]{2}{*}{ 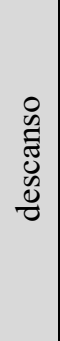 } & \multirow{2}{*}{ 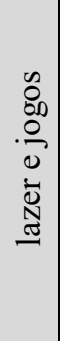 } & \multirow[t]{2}{*}{ 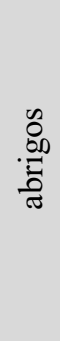 } & \multirow[t]{2}{*}{$\begin{array}{l}\widetilde{N} \\
\stackrel{\mathbb{U}}{\Xi} \\
. \Xi\end{array}$} & \multirow[t]{2}{*}{ 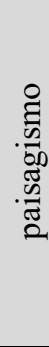 } \\
\hline & & & & & & & & 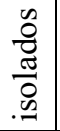 & 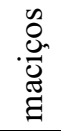 & & & & & & & \\
\hline $\begin{array}{l}\text { Área de lazer } 1 \text { - DIC } \\
\text { II }\end{array}$ & & & & & & & & & & & & 5 & 2 & 0 & 2 & 0 \\
\hline $\begin{array}{c}\text { Área de lazer } 1 \text { - Res. } \\
\text { Cosmos }\end{array}$ & & & & & & & & & & & & 1 & 0 & 0 & 2 & 0 \\
\hline $\begin{array}{c}\text { Área de lazer } 2 \text { - Res. } \\
\text { Cosmos }\end{array}$ & & & & & & & & & & & & 3 & 0 & 1 & 3 & 0 \\
\hline $\begin{array}{c}\text { Área de lazer } 3 \text { - Res. } \\
\text { Cosmos }\end{array}$ & & & & & & & & & & & & 0 & 0 & 0 & 0 & 0 \\
\hline $\begin{array}{l}\text { Área de lazer - Jd. } \\
\text { Florence }\end{array}$ & & & & & & & & & & & & 0 & 12 & 1 & 0 & 0 \\
\hline $\begin{array}{c}\text { Área de lazer - Jd. } \\
\text { Novo Maracanã }\end{array}$ & & & & & & & & & & & & 0 & 2 & 0 & 0 & 0 \\
\hline $\begin{array}{c}\text { Área de lazer - Pq. } \\
\text { Valença II }\end{array}$ & & & & & & & & & & & & 3 & 11 & 0 & 0 & 0 \\
\hline $\begin{array}{c}\text { Área de lazer - Jd. } \\
\text { Maracanã }\end{array}$ & & & & & & & & & & & & 0 & 14 & 0 & 7 & 0 \\
\hline $\begin{array}{l}\text { Área de lazer } 1 \text { - Jd. } \\
\text { Floresta }\end{array}$ & & & & & & & & & & & & 9 & 12 & 1 & 9 & 0 \\
\hline $\begin{array}{c}\text { Área de lazer } 2 \text { - Jd. } \\
\text { Floresta }\end{array}$ & & & & & & & & & & & & 0 & 9 & 0 & 1 & 0 \\
\hline $\begin{array}{c}\text { Área de lazer } 3 \text { - Jd. } \\
\text { Floresta }\end{array}$ & & & & & & & & & & & & 0 & 0 & 0 & 0 & 0 \\
\hline Área de lazer - DIC I & & & & & & & & & & & & 0 & 8 & 0 & 0 & 0 \\
\hline $\begin{array}{c}\text { Área de lazer - DIC } \\
\text { VI }\end{array}$ & & & & & & & & & & & & 7 & 10 & 0 & 2 & 0 \\
\hline $\begin{array}{c}\text { Área de lazer - Vida } \\
\text { Nova }\end{array}$ & & & & & & & & & & & & - & - & - & - & - \\
\hline $\begin{array}{c}\text { Área de lazer - Jardim } \\
\text { Vista Alegre }\end{array}$ & & & & & & & & & & & & 0 & 3 & 0 & 0 & 0 \\
\hline $\begin{array}{c}\text { Área de lazer } 1 \text { - } \\
\text { Parque Itajaí }\end{array}$ & & & & & & & & & & & & 2 & 3 & 0 & 0 & 0 \\
\hline $\begin{array}{c}\text { Área de lazer } 2 \text { - } \\
\text { Parque Itajaí }\end{array}$ & & & & & & & & & & & & 9 & 7 & 0 & 2 & 0 \\
\hline
\end{tabular}
Legenda

Atende ao atributo

Atende parcialmente ao atributo

Não atende ao atributo 
O Quadro 3, a seguir, apresenta de forma sintetizada as observações de cada um dos atributos estudados, além de uma breve comparação entre eles e as regiões de pesquisa. É importante ressaltar que, embora as duas regiões apresentem deficiências quanto ao atendimento a atributos essenciais para espaços de lazer, há diferenças substanciais em relação aos tipos existentes em cada uma das regiões, o que demonstra haver, portanto, uma distinção quanto à concepção e ao tratamento dessas áreas em ambas as regiões. De forma geral, observa-se que na região sudoeste há maior homogeneidade na distribuição dos atributos, em sua maior parte com atendimento parcial; já na região nordeste observa-se maior dicotomia entre atributos atendidos e não atendidos. Os atributos de localização, uso do solo no entorno e coesão são claramente negligenciados na região nordeste, o que se explica potencialmente pela forma como essas áreas estão inseridas no conjunto de enclaves fortificados produzidos pela forma de urbanização ali praticada. Atributos atinentes ao padrão paisagístico vinculado ao projeto - acessibilidade, delimitação dos espaços e vegetação -, ao contrário, ganham um pouco mais de qualidade, evidenciada por uma preocupação relacionada ao estereótipo desses espaços, condicionando-os a espaços de embelezamento diante do público de alto poder aquisitivo, que se utiliza desses cenários para manter seus imóveis valorizados. A paisagem bem desenhada é, nesse aspecto, importante condição, para a qual esses atributos concorrem.

\section{Discussão}

As "duas" periferias investigadas no município de Campinas padecem do mesmo problema: áreas de lazer pouco ou mal utilizadas, com qualidade urbanística e paisagística insuficiente. Surpreende constatar que apenas uma pequena parte dos espaços livres de uso público destinados nos planos de loteamentos em ambas as regiões foi utilizada efetivamente para sistemas de lazer; a maioria continua sem qualquer destinação. Considerando a importância desses sistemas para a realização de atividades físicas pela população, essa situação aponta para um descaso com a saúde pública. Se na região sudoeste parte dessas parcelas foi ocupada por moradias e equipamentos públicos comunitários, dando-lhes alguma destinação, ainda que de forma incongruente ao destino original, na região nordeste seu desprezo coloca em dúvida o papel do espaço público aberto para camadas da população que restringem suas esferas de sociabilidade nos espaços coletivos privativos, conforme constatou Mantey (2017) ao observar que, muitas vezes, os espaços privados de uso público como clubes e instituições (igrejas, institutos culturais), assim como locais totalmente privados tornam-se mais efetivos para a "fruição pública" que os locais totalmente públicos, especialmente nas periferias, como é o caso em Campinas.

As diferenças de qualidade entre as áreas de lazer nas duas regiões é outro aspecto a se considerar já que as demandas em termos de necessidades em ambas são distintas. Nesse âmbito, há uma distorção evidenciada pela própria estratégia corroborada pelo poder público em permitir a transformação de lotes privados em clubes esportivos e de lazer na região nordeste, o que desestrutura a análise comparativa. Em termos de intervenções, a região nordeste possui $8 \%$ de áreas de lazer, contra $11 \%$ na região sudoeste, uma diferença, portanto, pouco substancial. Entretanto, há que se observar que parte destas, na região nordeste, estão inscritas no interior das áreas muradas dos loteamentos, o que dificulta a intervenção mais direta do poder público. Isolando atributos como a acessibilidade social e a coesão, que, pela própria natureza dos tipos de tecidos urbanos murados, são de difícil atendimento na região nordeste, os atributos relacionados aos três princípios identificados por Robba e Macedo (2010) - valores ambientais, valores funcionais e valores estéticos - parecem estar mais presentes na região mais rica. Incidência maior de vegetação, sombreamentos e mobiliários de melhor qualidade, além de melhor manutenção (aspecto não analisado como atributo, mas observado em campo) na região nordeste indicam maior eficiência das políticas públicas nessa região. A desigualdade espacial em termos de quantidade e qualidade das áreas de lazer é um fenômeno que perpassa as periferias urbanas das cidades, o que demonstra a dificuldade de estruturá-las e consolidá-las, em especial nas mais pobres, além do valor que é atribuído ao espaço livre de uso público na urbanização contemporânea, em diferentes graus e contextos. O trabalho de Fan et al. (2017) constatou, através de um índice de acessibilidade verde (GAI), que as periferias de Shangai tiveram pouco progresso entre 2000 e 2010. A pesquisa de Hoffimann, Barros e Ribeiro (2017) também apontou que as distâncias médias a espaços verdes acessíveis nas áreas mais carentes da cidade do Porto, em Portugal, aumentaram e, além disso, os espaços verdes nessas áreas apresentaram mais problemas de segurança, danos, falta de equipamentos e atividades de lazer. Os trabalhos de Rigolon, Browning e Jennings (2018), Wei (2017) e Wolch, Byrne e Newell (2014) também evidenciaram desigualdade na distribuição e na qualidade dos parques entre localizações e cidades, com prejuízo para aquelas com mais presença de negros e pobres. 
Quadro 3 - Síntese dos atributos analisados nas regiões de estudo

\begin{tabular}{|c|c|c|}
\hline ATRIBUTOS & REGIÃO SUDOESTE & REGIÃO NORDESTE \\
\hline $\begin{array}{l}\text { Acessibilidade } \\
\text { física }\end{array}$ & \multicolumn{2}{|c|}{$\begin{array}{c}\text { Semelhança entre as regiões (avaliação equilibrada). Possuem diversos tipos de } \\
\text { barreiras em seu entorno. }\end{array}$} \\
\hline $\begin{array}{l}\text { Acessibilidade } \\
\text { social }\end{array}$ & $\begin{array}{l}\text { Do ponto de vista quantitativo, este foi } \\
\text { um dos itens mais bem atendidos, } \\
\text { embora duas áreas de lazer da região do } \\
\text { Ouro Verde sejam desconexas e } \\
\text { distantes da malha urbana adjacente. }\end{array}$ & $\begin{array}{c}\text { A maioria dos loteamentos é fechada e, } \\
\text { mesmo nas situações em que as áreas de lazer } \\
\text { estão localizadas em bairros abertos, seu } \\
\text { entorno é prejudicado pela presença dos } \\
\text { muros e de outros loteamentos fechados e } \\
\text { condomínios. }\end{array}$ \\
\hline $\begin{array}{l}\text { Acessibilidade } \\
\text { visual }\end{array}$ & \multicolumn{2}{|c|}{$\begin{array}{l}\text { Problemas relacionados à acessibilidade física e visual estão ligados às formas de } \\
\text { fechamento existentes nas áreas de lazer, incluindo os elementos naturais existentes. Na } \\
\text { região sudoeste o fator manutenção pesa negativamente. }\end{array}$} \\
\hline $\begin{array}{l}\text { Espaço de } \\
\text { permanência }\end{array}$ & $\begin{array}{l}\text { Equipamentos de descanso estão } \\
\text { instalados de forma quase aleatória ao } \\
\text { longo das áreas de lazer, sem haver } \\
\text { áreas determinadas e bem delimitadas. }\end{array}$ & $\begin{array}{l}\text { A quantidade de espaços de permanência e/ou } \\
\text { recreação passiva supera a da região } \\
\text { sudoeste. }\end{array}$ \\
\hline $\begin{array}{l}\text { Espaço de } \\
\text { movimento }\end{array}$ & \multicolumn{2}{|c|}{$\begin{array}{c}\text { Classificação equilibrada nas duas as regiões. Menor presença de áreas de lazer que } \\
\text { atendem parcialmente ao atributo. Em geral atendem ou não atendem. }\end{array}$} \\
\hline Coesão & \begin{tabular}{|c|} 
Muitas áreas de lazer nesta região são \\
delimitadas, mesmo que por vias ou por \\
algumas edificações de médio gabarito \\
(acima de um pavimento). A maioria \\
dos espaços aqui atendem parcialmente \\
ao atributo. \\
\end{tabular} & $\begin{array}{l}\text { Áreas de lazer são, muitas vezes, projetadas } \\
\text { nos limites do loteamento, fazendo com que } \\
\text { sua confrontação se dê com outros espaços } \\
\text { ainda não parcelados, o que prejudica a } \\
\text { coesão. Além disso, quando há o fechamento } \\
\text { por edificações, estas são de baixo gabarito. }\end{array}$ \\
\hline $\begin{array}{l}\text { Localização e } \\
\text { uso do solo }\end{array}$ & $\begin{array}{c}\text { As áreas de lazer mais próximas aos } \\
\text { eixos viários são beneficiadas com } \\
\text { maior diversidade de uso do solo. } \\
\text { Entretanto, a predominância do uso } \\
\text { monofuncional residencial resulta em } \\
\text { uma variação na avaliação desse } \\
\text { atributo. }\end{array}$ & $\begin{array}{l}\text { O uso monofuncional residencial é } \\
\text { predominante nesta região a considerar a } \\
\text { presença quase que exclusiva de loteamentos } \\
\text { fechados e condomínios. }\end{array}$ \\
\hline $\begin{array}{l}\text { Vegetação } \\
\text { (Maciços) }\end{array}$ & \multirow[b]{2}{*}{$\begin{array}{l}\text { Região árida e carente de vegetação de } \\
\text { ambas as formas e tamanhos. }\end{array}$} & \multirow{2}{*}{$\begin{array}{c}\text { Nesta região há maior equilíbrio no } \\
\text { atendimento a esse atributo, especialmente } \\
\text { nos loteamentos Caminhos de San Conrado e } \\
\text { Jardim Botânico, já que ambos recebem } \\
\text { manutenção constante de seus elementos } \\
\text { arbóreos, não só nas áreas de lazer, mas } \\
\text { também nas vias e espaços privados. }\end{array}$} \\
\hline $\begin{array}{l}\text { Vegetação } \\
\text { (Isolados) }\end{array}$ & & \\
\hline Sombreamento & $\begin{array}{l}\text { Atributo parcialmente atendido em } \\
\text { praticamente todos os casos estudados. }\end{array}$ & $\begin{array}{l}\text { Os casos aqui investigados tinham uma } \\
\text { condição melhor no atendimento a esse } \\
\text { atributo. }\end{array}$ \\
\hline $\begin{array}{l}\text { Iluminação } \\
\text { artificial }\end{array}$ & \multicolumn{2}{|c|}{$\begin{array}{l}\text { Há um equilíbrio entre as duas regiões, já que muitas áreas não possuem nenhum tipo de } \\
\text { posteamento para iluminação. Ao mesmo tempo, algumas áreas de lazer possuem } \\
\text { luminárias com absorção de energia solar. }\end{array}$} \\
\hline Mobiliários & $\begin{array}{c}\text { Os mobiliários da região sudoeste, } \\
\text { quando não ausentes, mostraram-se } \\
\text { mais precários. Há predominância de } \\
\text { aparelhos de ginástica ao ar livre ao } \\
\text { passo que os demais móveis foram } \\
\text { vistos em baixa quantidade (elementos } \\
\text { de cobertura - pontos de ônibus, bancos, } \\
\text { etc.). Predominam mobiliários de jogos } \\
\text { e lazer. }\end{array}$ & $\begin{array}{l}\text { Embora em menor quantidade, os mobiliários } \\
\text { desta região são mais variados e estão em } \\
\text { melhor qualidade do que na região sudoeste } \\
\text { (bancos, paisagismo, coberturas, playground). }\end{array}$ \\
\hline
\end{tabular}


Esta pesquisa apenas confirma o que a literatura já vem apontando, mas apresenta algumas peculiaridades em termos de estratégias e quanto aos atributos analisados.

Embora não tenha sido objetivo da pesquisa analisar o grau de importância de cada atributo para uma utilização mais efetiva das áreas de lazer, tampouco verificar como cada um interfere nas decisões quanto ao uso ou não desses espaços, a literatura mostra que algumas características e alguns atributos espaciais são essenciais para ativá-los, com destaque para a questão da acessibilidade. Hillsdon (2006) já havia constatado que não há evidências de uma relação clara entre atividades recreativas e acessibilidade às áreas verdes. Pesquisas posteriores, entretanto, refinaram esse resultado, demonstrando que essa questão é mais complexa. $\mathrm{O}$ artigo de Giles-Corti et al. (2005) demonstrou que áreas de lazer bem desenhadas encorajam a realização de atividades físicas, sendo que o efeito se torna ainda mais robusto para distâncias curtas, maior presença de atratividades e tamanhos maiores. Distâncias às áreas de lazer menores que $600 \mathrm{~m}$ interferem em sua efetiva utilização para a realização de atividades físicas, mas a distância, como fator isolado, não é suficiente para que os moradores da vizinhança as utilizem - o tamanho (áreas maiores que cinco hectares) e fatores relacionados com facilidades para pessoas com mobilidade reduzida devem compor o conjunto de atributos necessários (SCHIPPERIJN et al., 2010). Hooper et al. (2018), ao analisar vários padrões para verificar correlações entre áreas de lazer e atividades físicas moderadamente vigorosas, constatou que apenas um padrão desse tipo de espaço foi associado a um resultado de saúde mais representativo: periferias onde $95 \%$ dos moradores moravam a menos de $400 \mathrm{~m}$ de um parque tinham probabilidade três vezes maior de fazer atividades físicas semanais. O planejamento das áreas de lazer, desde sua definição nas diretrizes de orientação para os projetos de loteamento até a implantação de um sistema de áreas livres, no momento da implantação paisagística, é também decisivo para torná-las bem-sucedidas. Bahrini, Bell e Mokhtarzadeh (2017) identificou em Teerã, no Irã, que os parques pouco integrados no interior dos bairros urbanos mostraram-se com menor nível de manutenção, pouco utilizados e com mais vandalismo. As áreas de lazer deveriam ser projetadas de modo a que fossem integradas ao tecido urbano, apoiando viagens ativas para outros destinos, em um sistema interligando os maiores com os menores, conforme aponta Stewart et al. (2018). A configuração de um sistema de espaços livres de uso público interligados e integrados à malha urbana é uma estratégia que vai além da simples questão de seus atributos internos, mas que poderia dar um salto de qualidade no tocante à acessibilidade. De mais difícil solução na região nordeste, devido ao conjunto de enclaves murados, a região sudoeste possibilitaria a construção de corredores e espaços de caminhabilidade junto aos eixos principais de acesso, conforme é possível visualizar no mapa da Figura 13. A quantidade de espaços livres e de uso público não equipados (representados pelos pontos em vermelho escuro) dá a ideia do potencial existente nesse sentido.

A presença dos atributos interfere direta ou indiretamente nas questões essenciais quanto ao uso das áreas de lazer. Assim é, por exemplo, a relação entre vegetação e sombreamento (para maior conforto dos usuários), a diversidade de atrativos (ligados à presença de mobiliários e uso do solo diversificado), a iluminação, a visibilidade e maior diversificação dos atrativos e usos para os aspectos da segurança. O trabalho de Kostrzewska (2017) confirmou que a utilização dos espaços para atividades físicas depende essencialmente do atendimento às necessidades (nem sempre tão óbvias quanto parecem) dos diferentes grupos sociais, além da importância da população usuária na participação do projeto e na construção do processo e design estético. O trabalho de Yen et al. (2017) mostrou que a percepção relacionada com a segurança e as atitudes pessoais teve uma associação mais significativa com as intenções de uso do que a percepção quanto à acessibilidade e utilidade predeterminadas programaticamente. Isso pode ter relação com o que constatou Hoffimann, Barros e Ribeiro (2017) sobre a relação entre os espaços que possuem menos amenidades, como assentos, banheiros, cafés, sinais de danos e maiores problemas com segurança. Salvo et al. (2017) reforça a importância dos chamados parques pop ups no âmbito do chamado urbanismo tático como estratégia para aumentar a presença de usuários. A questão da vegetação é destacada no artigo de Benchimol et al. (2017), que, ao analisar as praças no município de São Paulo, constataram que os gestores públicos não enxergam seu potencial ambiental, razão pela qual consideram que muitas delas não deveriam ter vegetação. Assim é que a incompletude ou a insuficiência de determinados atributos espaciais podem comprometer sua efetiva utilização de forma mais plena, democrática, ampla (para diferentes grupos sociais) e livre. O alcance dos objetivos relacionados com as práticas de lazer e esportivas, condições para aumentar a saúde física e mental das pessoas (WOOD, 2017) depende, portanto, de uma combinação de fatores e de atributos presentes.

\section{Considerações finais}

Ao apresentar a configuração das áreas de lazer implantadas em duas regiões periféricas de Campinas com características sociodemográficas diferentes, foi possível constatar que a questão teve pouca relevância no 
âmbito das políticas públicas adotadas no município em ambas nos últimos 50 anos. Em parte, mesmo com as diferenças constatadas em termos de atributos (e suas insuficiências), pode-se concluir que essa política não foi efetiva em nenhuma das regiões, substituída, entretanto, pelas iniciativas empregadas nos empreendimentos privados na região nordeste, com a implantação de clubes privados. Diante da natureza das ocupações e das opções possíveis a essa população de acordo com seu poder aquisitivo, pode-se sugerir que as exigências legais (Lei federal $n^{\circ} 6.766$ (BRASIL, 1979)) não possuem a mesma eficácia nas duas regiões. Posturas projetivas em relação a esses espaços nos planos de loteamento é uma questão importante de ser observada. As pequenas áreas de lazer localizadas na malha viária projetada multiplicam-se em alguns empreendimentos, como no caso do Alphaville (na região nordeste). Entretanto, quando essas áreas não compõem a totalidade mínima exigida pela municipalidade como doação pública, o excedente acaba sendo doado em forma de vastas áreas, que acabam se tornando impróprias para uso, tanto por sua escala e por seu uso originário (como é o caso de APP doadas como praças/espaços de lazer), como pela falta de atuação pública sobre elas. Já na região sudoeste, a própria pressão exercida por uma demanda reprimida carente de novas moradias força que áreas antes destinadas ao lazer acabem por abrigar habitações populares e outros equipamentos públicos comunitários. Não é estranho que essas distorções ocorram quando o município não possui uma política de terras para suprir o déficit e a demanda habitacionais.

Percebe-se assim uma incongruência em relação à pertinência da legislação, principalmente municipal, que exige a destinação de áreas públicas sem nenhum tipo de determinação para que recebam uma efetivação de seu uso através da implantação de equipamentos, tornando-as grandes espaços "vazios" que permeiam a malha urbana, à sorte das necessidades que recaem sobre elas. Nesse aspecto, é possível propor formas de revisar as disposições normativas para garantir que essas áreas não permaneçam como "vazios", sem cumprimento de sua função social. Uma dessas propostas de revisão é levar em consideração os atributos aqui apresentados, entre outros, como forma de analisar a qualidade espacial do que tem sido projetado e oferecido ao público, permitindo maior usabilidade. Políticas de compensação poderiam ser pensadas de forma a permitir que destinações de áreas públicas em empreendimentos que já terão suas áreas de lazer privativamente efetivadas possam ser substituídas pecuniariamente, utilizando-se tais recursos para a implantação de novas áreas de lazer em terrenos já destinados. Além disso, compreende-se necessário verificar efetivamente os programas a serem designados, para que essas áreas possam atender, de fato, aos verdadeiros anseios e demandas da população moradora no entorno, conhecendo-se suas especificidades e necessidades.

\section{Referências}

ABREU, M. de A. O crescimento das periferias urbanas nos países do Terceiro Mundo: uma apresentação do tema. In: SANTOS, M.; SOUZA, M. A. A. (Org.). A construção do espaço. São Paulo: Nobel, 1986.

ANGULURI, R.; NARAYANAN, P. Role of green space in urban planning: outlook towards smart cities. Urban Forestry \& Urban Greening, v. 25, p. 58-65, 2017.

ASHIHARA, Y. El diseño de espacios exteriores. Barcelona: Gustavo Gilli, 1981.

BAENINGER, R. Espaço e tempo em Campinas: migrantes e a expansão do pólo industrial paulista. Campinas: CMU; Unicamp, 1996.

BAHRINI, F.; BELL, S.; MOKHTARZADEH, S. The relationship between the distribution and use patterns of parks and their spatial accessibility at the city level: a case study from Tehran, Iran. Urban Forestry \& Urban Greening, v. 27, p. 332-342, 2017.

BENCHIMOL, J. F. et al. Decentralized management of public squares in the city of São Paulo, Brazil: implications for urban green spaces. Land Use Policy, v. 63, p. 418-427, 2017.

BERNARDO, R. G. Histórico da ocupação do solo do Município de Campinas. São Paulo, 2002. Dissertação (Mestrado em Arquitetura e Urbanismo) - Faculdade de Arquitetura e Urbanismo, Universidade de São Paulo, São Paulo, 2002.

BOWLER, D. et al. Urban greening to cool towns and cities: a systematic review of the empirical Evidence. Landscape and Urban Planning, v. 97, p. 147-155, 2010.

BRASIL. Lei no 6.766, de 19 de dezembro de 1979, que dispõe sobre o Parcelamento do Solo Urbano e dá outras Providências. Diário Oficial da União, 20 de dezembro de 1979. p. 19457, col. 1.

CARR, S. et al. Public space. Cambridge: Cambridge University Press, 1995. 
CUNHA, J. M. P. da; FALCÃO, C. A. Campinas metropolitana: diversidades socioespaciais da virada para o século XXI. Campinas: Librum, 2017.

CUNHA, J. M. P. da; JAKOB, A. A. E. Segregação socioespacial e inserção no mercado de trabalho na Região Metropolitana de Campinas. Revista Brasileira de Estudos de População, v. 27, n. 1, p. 115-139, 2010.

FAN, P. et al. Accessibility of public urban green space in an urban periphery: the case of Shanghai. Landscape and Urban Planning, v. 165, p. 177-192, 2017.

GILES-CORTI, B. et al. Increasing walking: how important is distance to, attractiveness, and size of public open space? American Journal of Preventive Medicine, v. 28, n. 2, p. 169-176, 2005.

HILLSDON, M. et al. The relationship between access and quality of urban green space with population physical activity. Public Health, v. 120, n. 12, p. 1127-1132, 2006.

HOFFIMANN, E.; BARROS, H.; RIBEIRO, A. Socioeconomic inequalities in green space quality and accessibility: evidence from a Southern European city. International Journal of Environmental Research and Public Health, v. 14, n. 8, p. 916-932, 2017.

HOOPER, P. et al. Testing spatial measures of public open space planning standards with walking and physical activity health outcomes: findings from the Australian national liveability study. Landscape and Urban Planning, v. 171, p. 57-67, 2018.

JACOBS, J. Morte e vida de grandes cidades. São Paulo: WMF Martins Fontes, 2000.

KOSTRZEWSKA, M. Activating public space: how to promote physical activity in urban environment. IOP Conf. Series: Materials Science and Engineering v. 245, n. 5, 2017.

LIMA, A. M. L. P. et al. Problemas de utilização na conceituação de termos como espaços livres, áreas verdes e correlatos. In: CONGRESSO BRASILEIRO DE ARBORIZAÇÃO URBANA, 2., São Luís, 1994. Anais [...] São Luís: imprensa EMATER/MA, 1994.

MACEDO, S. S. Espaços livres. Paisagem e Ambiente, São Paulo, n. 7, p. 15-56, jun. 1995.

MACEDO, S. S. QUAPÁ-SEL: um projeto de pesquisa em rede. In: ENCONTRO NACIONAL DA ASSOCIAÇÃO NACIONAL DE PESQUISA E PÓS-GRADUAÇÃO EM ARQUITETURA E URBANISMO, 1., Rio de Janeiro, 2010. Anais [...] Rio de Janeiro, 2010.

MANTEY, D. The 'publicness' of suburban gathering places: the example of Podkowa Leśna (Warsaw urban region, Poland). Cities, v. 60, p. 1-12, 2017.

MASCARÓ, J. L. Infra-estrutura da paisagem. Porto Alegre: Masquatro, 2008.

MASCARÓ, L.; MASCARÓ, J. L. Vegetação urbana. 3. ed. Porto Alegre: Masquatro, 2010.

QUEIROGA, E. F. A megalópole e a praça: o espaço entre a razão de dominação e a ação comunicativa. São Paulo, 2001. Tese (Doutorado em Arquitetura e Urbanismo) - Faculdade de Arquitetura e Urbanismo, Universidade de São Paulo, São Paulo, 2001.

QUEIROGA, E. F. Sistemas de espaços livres e esfera pública em metrópoles brasileiras. Resgate: Revista Interdisciplinar de Cultura, v. 19, n. 1, p. 25-35, 2012.

REIS, N. G. Notas sobre urbanização dispersa e novas formas de tecido urbano. São Paulo: Via das Artes, 2006.

RIGOLON, A.; BROWNING, M.; JENNINGS, V. Inequities in the quality of urban park systems: an environmental justice investigation of cities in the United States. Landscape and Urban Planning, v. 178, p. 156-169, 2018.

ROBBA, F.; MACEDO, S. Praças Brasileiras. São Paulo: EDUSP, 2010.

SALVO, D. et al. Impacts of a temporary urban pop-up park on physical activity and other individual- and community-level outcomes. Journal of Urban Health, v. 94, p. 470-481, 2017.

SCHIPPERIJN, J. et al. Influences on the use of urban green space: a case study in Odense, Denmark. Urban Forestry \& Urban Greening, v. 9, n. 1, p. 25-32, 2010.

SENNETT, R. O declínio do homem público: as tiranias da intimidade. São Paulo: Record, 2014.

SERPA, A. O Espaço público na cidade contemporânea. São Paulo: Contexto, 2014. 
SITTE, C. A construção das cidades segundo seus princípios artísticos. São Paulo: Ática, 1992.

STEWART, O. et al. Why neighborhood park proximity is not associated with total physical activity. Health and Place, v. 52, p. 163-169, 2018.

VILLAÇA, F. O espaço intraurbano no Brasil. São Paulo: Nobel, 2001.

WEI, F. Greener urbanization?: changing accessibility to parks in China. Landscape and Urban Planning, V. 157, p. 542-552, 2017.

WOLCH, J. R.; BYRNE, J.; NEWELL, J. P. Urban green space, public health, and environmental justice: the challenge of making cities 'just green enough'. Landscape and Urban Planning, v. 125, p. 234-244, 2014.

WOOD, L. et al. Public green spaces and positive mental health: investigating the relationship between access, quantity and types of parks and mental wellbeing. Health \& Place, v. 48, p. 63-71, 2017.

YEN, Y. et al. The predictors of the behavioral intention to the use of urban green spaces: the perspectives of young residents in Phnom Penh, Cambodia. Habitat International, v. 64, p. 98-108, 2017.

Faculdade de Engenharia Civil, Arquitetura e Urbanismo | Universidade Estadual de Campinas | Rua Saturnino de Brito, 224 | Campinas SP - Brasil | CEP 13083-889 | Tel.: (19)3521-3446 | E-mail: spiochi@unicamp.br

\section{Carolina Guida Cardoso do Carmo}

Faculdade de Engenharia Civil, Arquitetura e Urbanismo | Universidade Estadual de Campinas | Tel.: (19) 98809-9684 | E-mail: carolinagcdocarmo@gmail.com

\section{Ambiente Construído}

Revista da Associação Nacional de Tecnologia do Ambiente Construído

Av. Osvaldo Aranha, $99-3^{\circ}$ andar, Centro

Porto Alegre - RS - Brasil

CEP $90035-190$

Telefone: +55 (51) 3308-4084

Fax: +55 (51) 3308-4054

www.seer.ufrgs.br/ambienteconstruido

E-mail: ambienteconstruido@ufrgs.br 